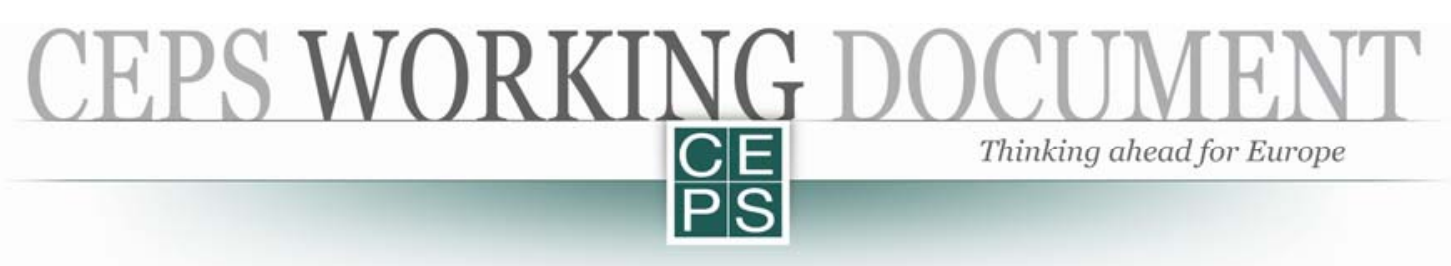

\title{
EU Policy on Climate Change Mitigation since Copenhagen and the Economic Crisis
}

\section{Christian Egenhofer and Monica Alessi}

\author{
No. 380 / March 2013
}

\begin{abstract}
The EU has long assumed leadership in advancing domestic and international climate change policy. While pushing its partners in international negotiations, it has led the way in implementing a host of domestic measures, including a unilateral and legally binding target, an ambitious policy on renewable energy and a strategy for low-carbon technology deployment. The centrepiece of EU policy, however, has been the EU Emissions Trading System (ETS), a cap-and-trade programme launched in 2005. The ETS has been seen as a tool to ensure least-cost abatement, drive EU decarbonisation and develop a global carbon market. After an initial review and revision of the ETS, to come into force in 2013, there was a belief that the new ETS was 'future-proof', meaning able to cope with the temporary lack of a global agreement on climate change and individual countries' emission ceilings. This confidence has been shattered by the simultaneous 'failure' of Copenhagen to deliver a clear prospect of a global (top-down) agreement and the economic crisis. The lack of prospects for national caps at the international level has led to a situation whereby many member states hesitate to pursue ambitious climate change policies. In the midst of this, the EU is assessing its options anew. A number of promising areas for international cooperation exist, all centred on the need to 'raise the ambition level' of GHG emission reductions, notably in aviation and maritime, short-lived climate pollutions, deforestation, industrial competitiveness and green growth. Public policy issues in the field of technology and its transfer will require more work to identify real areas for cooperation.
\end{abstract}

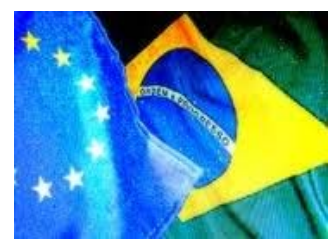

This study was prepared in the context of the CEPS-FRIDE project on the EU-Brazil Strategic Partnership, funded by the Gulbenkian Foundation. CEPS Working Documents are intended to give an indication of work being conducted within CEPS' research programmes and to stimulate reactions from other experts in the field. The views expressed in this paper are those of the authors and do not necessarily represent any institution with which they are affiliated.
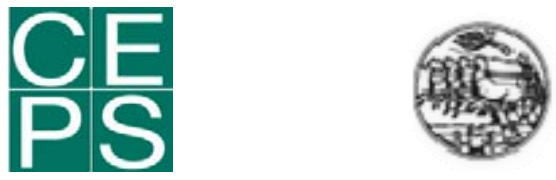
FUNDAÇÃO CALOUSTE GULBENKIAN

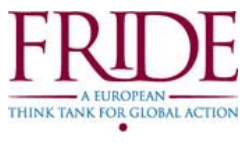

ISBN 978-94-6138-290-0

Available for free downloading from the CEPS website (http://www.ceps.eu)

(C) CEPS 2013 


\section{Contents}

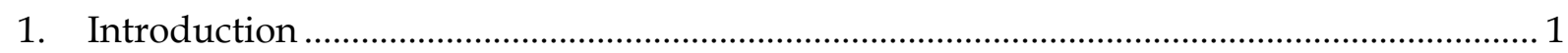

2. The EU's climate change policy in the run-up to Copenhagen ............................................ 1

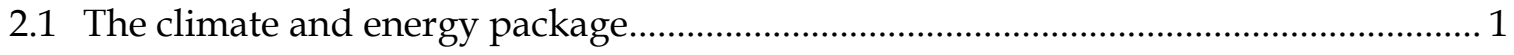

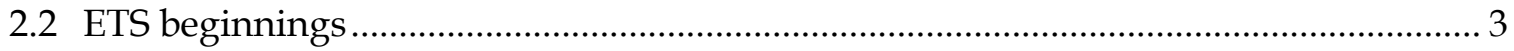

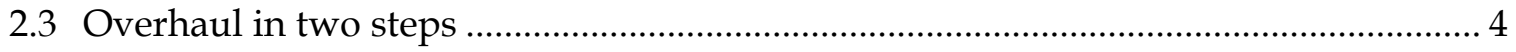

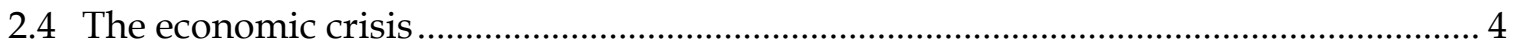

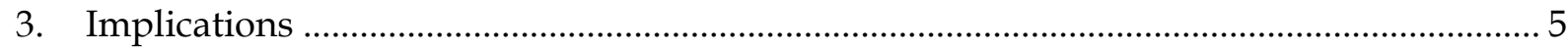

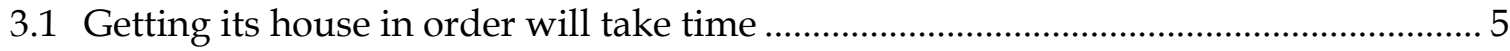

3.2 The EU's share of global emissions is falling fast.......................................................... 6

3.3 Industrial competitiveness does matter .......................................................................... 7

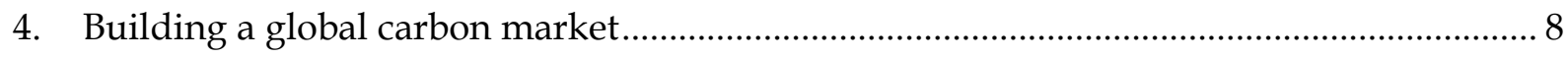

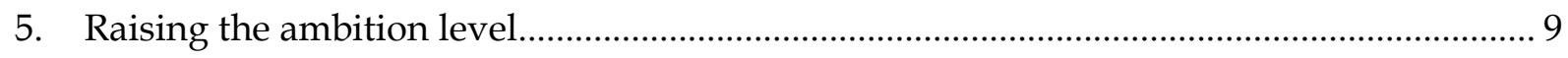

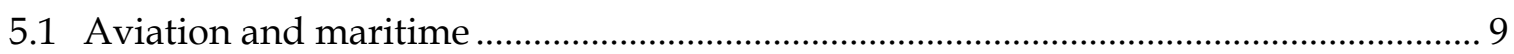

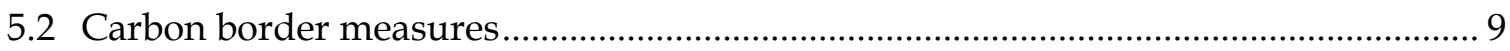

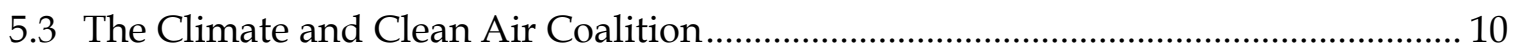

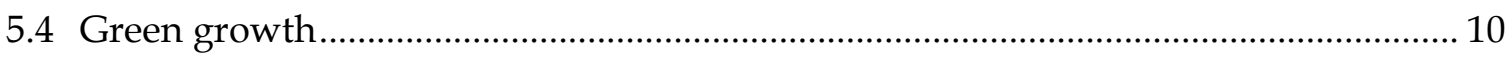

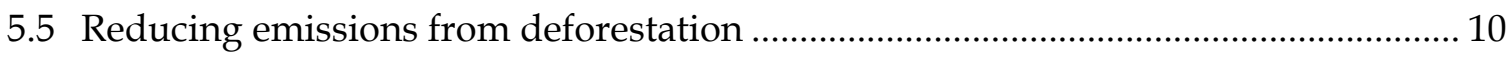

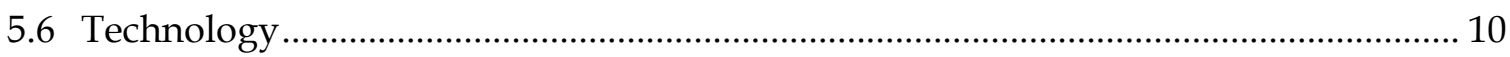

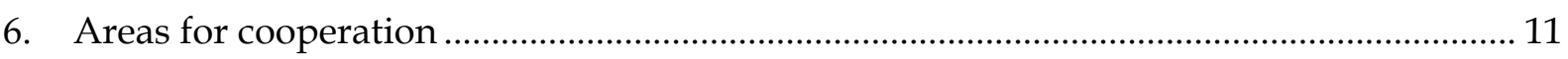

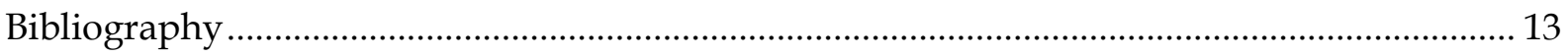

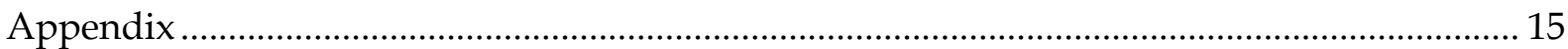




\title{
EU Policy on Climate Change Mitigation since Copenhagen and the Economic Crisis
}

\author{
Christian Egenhofer and Monica Alessi*
}

CEPS Working Document No. 380 / March 2013

\section{Introduction}

As is well known, the EU has identified tackling climate change as one of the world's greatest challenges. It has repeatedly confirmed its position that an increase in the global, annual, mean surface temperature should not exceed $2^{\circ} \mathrm{C}$ above pre-industrial levels. After the withdrawal of the US from the Kyoto Protocol, the EU found itself being catapulted into global 'leadership' on climate change. While few had bet at the time that the Kyoto Protocol would survive, instead (not at least owing to active EU diplomacy) Japan, Canada and Russia ratified the Protocol to bring it into force in 2005. As a result, the EU has adopted numerous laws both to fulfil its commitments and to prepare the path for a new post-2012 agreement or at least a framework. Among them have been a host of policies to support renewable energy, improve energy efficiency, decarbonise transport and advance a strategy on low-carbon technology deployment. The centrepiece of the EU's climate change policy has been the EU Emissions Trading Scheme (EU ETS), which started in 2005. Yet the outcome of the Copenhagen summit in December 2009 and the continuing economic crisis have triggered a rethinking of the EU's strategy. The new strategy is still emerging, with its implications for relations with third countries being unclear. Nevertheless, a few pointers and issues for further discussion can be highlighted.

\section{The EU's climate change policy in the run-up to Copenhagen}

Identifying the scope for cooperation between the EU and emerging economies like Brazil requires an understanding of the EU's climate change 'narrative' prior to the 2009 climate summit in Copenhagen. It also requires acknowledging how difficult it is to change a onceachieved consensus or modify a negotiation position of the EU, which for strategically important issues, such as the long-term international strategy, requires a broad consensus within the EU. The current situation, in which Poland plus a number of other Central and Eastern European member states are continually opposed to an increase in the level of ambition, i.e. more onerous targets, is a case in point.

\subsection{The climate and energy package}

The EU's climate change policy has long been based on the EU's long-term target to limit the global temperature increase to a maximum of two degrees Celsius above pre-industrial levels. To achieve this, the EU set a number of targets as well as a host of accompanying policies, generally referred to as the 'climate and energy package' or the '20 20 by 2020 targets':

\footnotetext{
* Christian Egenhofer is Associate Senior Research Fellow at CEPS (Brussels) and Visiting Professor, College of Europe (Bruges \& Natolin), SciencesPo (Paris) and LUISS University (Rome). Monica Alessi is Programme Manager, Environmental Policy, at CEPS.
} 
1) a binding, absolute, emissions reduction commitment of $30 \%$ by 2020 compared with 1990 conditional on a global agreement, and a 'firm independent commitment' to achieve at least a $20 \%$ reduction;

2) a binding target to reach a $20 \%$ share of renewable energy sources in primary energy consumption by 2020;

3) a binding minimum target of increasing the share of renewables in each member state's transport energy consumption to $10 \%$ by 2020 (this target initially focused solely on biofuels, but was later widened to include other forms of renewable energy sources);

4) a $20 \%$ reduction of primary energy consumption by 2020 compared with projections (non-binding); and

5) a commitment to enable the construction of up to 12 large-scale power plants using carbon capture and storage (CCS) technology.

The climate and energy package was finally adopted in April 2009 and contains six principal elements. These entail a directive for the promotion of renewable energy sources, a revised EU ETS starting in 2013, an 'effort sharing' decision that sets binding emission targets for EU member states in sectors not subject to the ETS, a regulation to reduce by 2015 average $\mathrm{CO}_{2}$ emissions of new passenger cars to $120 \mathrm{~g} / \mathrm{km}$, new environmental quality standards for fuels and biofuels (aimed at reducing by 2020 GHG emissions from fuels by $6 \%$ over their entire life-cycle) and a regulatory framework for CCS. Prior to that, the EU had already published the Strategic Energy Technology (SET-)Plan to strengthen research, development and demonstration as well as early deployment help for new low-carbon energy technologies.

While climate change was the main driver, the 'package' was equally meant to address energy policy challenges. Domestic energy resources have been dwindling at the same time as government intervention in the energy industry has been on the rise in precisely those countries that could potentially fill the gap. In this context, the EU and its member states have been examining domestic and external policy options to move to a more sustainable and secure energy supply. These include, among others, investing in renewable energy sources, promoting CCS technology and investing in nuclear energy in member states that wish to do so. Renewables policy has been guided by the need for large-scale deployment to bring down the costs of technology.

Additional real or perceived advantages of the EU's climate and energy package have included the following:

- the renewable energy policy can provide for technological leadership in sun-rise technologies;

- $\quad$ renewable electricity can reduce long-term electricity prices and their volatility;

- the substitution of fossil fuels combined with renewables may reduce the pricing power of Russia (notably on gas); and

- the introduction of the EU ETS can lead to the retention by importing countries of some of the economic rent of producer countries.

To offset the higher prices for both industry and domestic consumers, energy efficiency has been perceived as a central piece, certainly for the transition period until new technologies and new fuels become available on a large scale. With increasing prices, reducing consumption gives a reasonable prospect for keeping the energy bill constant.

There has been an additional aspect of the '20 20 by 2020' targets that is often overlooked. The first phase of the EU ETS showed that setting a hard cap on GHG emissions in the EU is 
next to impossible without some sort of legally binding constraint. In a scenario of a post2012 agreement without absolute caps, it was and still is difficult to see how the EU ETS could continue to exist in a meaningful way. Member states and the European Commission would most likely not be able to impose an ambitious emissions ceiling on industry without a legally binding constraint. The '20 20' targets were meant to address this risk.

At the heart of the agreement are the ' 2020 by 2020' targets. In addition to the revised EU ETS - covering power and industry emissions - which has fixed by law a legally binding target for perpetual, annual reductions by $1.74 \%, 1$ implementation of these targets has been operationalised by the introduction of legally binding targets for GHG emission reductions at the member state level ranging from $-20 \%$ to $+20 \%$, depending on the member state. ${ }^{2}$ Also the $20 \%$ renewable target by 2020 - which translates into roughly a $35 \%$ share of renewables in the power sector - has been broken down into differentiated national targets (see Table A1 in the appendix) for the share of renewable energy sources in final energy consumption and introduced. The EU's cornerstone: The Emissions Trading System

The EU ETS has been designed as a domestic policy, largely 'protected' from carbon markets that at the time were seen as emanating from the Kyoto Protocol. The principal reason has been concerns over compliance under the Kyoto Protocol and the Marrakech Accords. For an efficient trading system to work, there has to be a guarantee that compliance is ensured with a possibility of recourse to a court in case of litigation.

By covering currently some 2 billion of GHG emissions in the EU and the European Economic Area (EEA), ${ }^{3}$ the EU ETS by most estimates makes up some $80 \%$ of the global carbon market. Strictly speaking a regional carbon market, its size nonetheless means that prices for EU allowances (EUAs) under the ETS set the prices for the global carbon market. With demand from those countries that have ratified the Kyoto Protocol fast decreasing, the EU ETS will become - at least temporarily - an even more important component of the global carbon market.

\subsection{ETS beginnings}

The well-publicised initial problems of the ETS were partly the result of the rapid speed with which the ETS was adopted, motivated by the EU's desire to show its strong determination to tackle climate change. This should, however, not hide the fact that the ETS suffered from some serious design flaws (e.g. Egenhofer, 2007; Swedish Energy Agency, 2007, Ellerman, Convery and de Perthuis, 2010). The initial allocation of allowances by member states on the basis of National Allocation Plans led to a 'race to the bottom', i.e. member states were under pressure by industries not to hand out fewer allowances than their EU competitors received. This led to over-allocation and ultimately to a price collapse. During the period when the EU allowance price was high, free allocation also generated 'windfall profits', mainly but not only in the power sector. Some of these issues were addressed in phase 2 (2008-12) as a result of member state cooperation and the European Commission being able to reduce member states' allocation proposals. Still, throughout both phases, by and large the ETS has managed to deliver a carbon price. One result has been that the carbon price has now clearly entered boardroom discussions (Ellerman and Joskow, 2008).

In the absence of a global agreement and 'uneven' carbon constraints, the answer to concerns over competitiveness and carbon leakage has been free allocation. Free allocation constitutes

\footnotetext{
${ }^{1}$ This figure allows for a 21\% GHG emissions reduction in 2020 compared with 2005.

2 These are referred to as 'effort sharing' targets, covering transport, building or waste and amounting EU-wide to a $10 \%$ reduction below 2005 levels by 2020 .

${ }^{3}$ The EEA countries Norway, Iceland and Liechtenstein are fully integrated into this market.
} 
compensation, potentially creating an incentive to continue producing carbon in Europe (Ellerman, Convery and de Perthuis, 2010).

\subsection{Overhaul in two steps}

Experiences from phase 1 and 2 have greatly helped the European Commission to propose and adopt radical changes to the EU ETS, which were not even thinkable before its initial adoption in 2003.4 The principal element of the new ETS is a single EU-wide cap, which will decrease annually in a linear way by $1.74 \%$ starting in 2013 . This linear reduction continues beyond 2020, as there is no sunset clause.

The revised ETS Directive also foresees EU-wide harmonised allocation rules. Starting from 2013, power companies will have to buy all their emission allowances at an auction with some temporary exceptions for 'coal-based' poorer member states. At the same time, the industrial sectors under the ETS that are exposed to significant non-EU competition and thereby potentially subject to carbon leakage will receive $100 \%$ of allowances free of charge up to 2020 .

Other changes include restrictions to the total volume of Clean Development Mechanism (CDM)/Joint Implementation (JI) credits, the use of 300 million EU allowances to finance the demonstration of CCS and innovative renewable technologies. Furthermore, there is a general - non-legally binding - commitment by EU member states to spend at least half of the revenues from auctioning on tackling climate change in both the EU and developing countries, including on measures to avoid deforestation and increase afforestation and reforestation in developing countries. In addition,

- $\quad$ the system will be extended to aviation, the chemicals and aluminium sectors and to other GHGs, e.g. nitrous oxide from fertilisers and perfluorocarbons from aluminium; and

- member states can financially compensate electro-intensive industries for higher power prices. The European Commission has drawn up EU guidelines to this end.

As in the previous periods, access to project credits under the Kyoto Protocol from outside the EU will be limited. The revised ETS will restrict access to no more than $50 \%$ of the reductions required in the EU ETS to ensure that emission reductions will happen in the EU. Leftover CDM/JI credits from 2008-12 can be used until 2020.

\subsection{The economic crisis}

At the time of the hard-won compromise of the ETS review for post-2012, there was a general conviction that the new ETS would be 'future-proof', i.e. be able to cope with the temporary lack of a global climate change agreement and address competitiveness, yet able to drive decarbonisation of the EU economy. The 2008-09 economic crisis, however, has destroyed that confidence by a seemingly permanent dramatic lowering of EUA prices due to a rapid and dramatic decline in economic output. Ever since, EUA prices have been lingering below $€ 5$ per tonne of $\mathrm{CO}_{2}$, going as low as around $€ 2$. Without political intervention, EUA prices are not expected to climb much higher throughout the period of up to 2020, largely because of the possibility to bank unused allowances between the second and third phase (European Commission, 2012).

When measured against 2007 levels, the EU's current pledge of 20\% compares poorly with the pledges of other industrialised countries. The current $-20 \%$ pledge is inferior in terms of

\footnotetext{
${ }^{4}$ See e.g. Ellerman, Convery and de Perthuis (2010), Skjærseth and Wettestad (2010) and Egenhofer et
} al. (2011) for a full overview. 
the effort required to those of the US or Canada, while a 30\% reduction pledge would still be weaker than the upper-end pledges of Australia and Japan (e.g. Spencer et al., 2010; Den Elzen et al., 2009).

The implication of the lack of ambition goes beyond the EU's domestic decarbonisation strategy. The EU's minimum target is likely to lie above the trajectory implied by a linear reduction from current levels towards a 2050 target to reach the long-term target of reducing "emissions by $80-95 \%$ by 2050 compared to 1990 levels", the EU's politically accepted objective. This would mean that an EU reduction target of $20 \%$ would not seem to enable the world to reach its envisaged objective under reasonable assumptions (e.g. Ward and Grubb, 2009). This has been indirectly acknowledged by the European Commission in the Staff Working Paper accompanying the 26 May 2010 Communication, which states that "internal reductions by 2020 at a higher level than the reference case (which achieves the $-20 \%$ target internally) is more in line with a $2^{\circ} \mathrm{C}$ compatible scenario" (European Commission, 2010b).

A low level of ambition in the EU is equally unlikely to facilitate an ambitious international agreement consistent with long-term objectives and economic efficiency. The European Commission's own analysis already in 2009 (European Commission, 2009) noted that a 30\% reduction target combined with a carbon market for the group of developed countries would cut global mitigation costs by about a quarter. Sticking to a $20 \%$ target would forego these potential benefits.

Finally, a lack of ambition is in gross contradiction of the EU's rhetoric on how to generate financing for mitigation and adaptation to climate change in developing countries. The EU envisages the majority of these financial flows coming through the carbon market. Under a $20 \%$ reduction pathway and the possibility to import credits through the Kyoto Protocol's flexible mechanisms, the resulting EU carbon price is likely to be too low to generate a significant portion of the $\$ 100$ billion p.a. post-2012 that has been agreed.

\section{Implications}

The EU's low level of ambition affects its influence in international fora when discussing climate change policy. The emergence of new, important global players (in particular BRIC 5 countries) with a large potential to reduce emissions - but also to increase them if no action is taken - requires a delicate diplomatic effort, as well as willingness to support effectively a change of track. The share of EU emissions in global emissions is decreasing (due in large part to the increases in emerging economies), which in turn brings adverse domestic incentives and puts into question the EU's climate policy. There is thus a need to reconcile the EU's rhetoric with its own ambitions, first by getting its house in order and second by engaging more meaningfully with emerging countries willing to participate constructively in reducing emissions.

\subsection{Getting its house in order will take time}

The first implication is that the EU will need to get its house in order. An initial step has been taken with a European Commission proposal ${ }^{6}$ to stagger the release of EUAs to be auctioned,

\footnotetext{
${ }^{5}$ BRIC refers to Brazil, Russia, India and China.

6 The proposal consists of the following elements: i) a proposal to amend the EU ETS Directive and clarify the prerogative of the EC to make changes to the auctioning profile within a trading period through the Climate Change Committee; ii) an amendment to the Auctioning Regulation that does not include the number; and iii) a Staff Working Document (SWD) that outlines, in some detail, the rationale behind back-loading as well as at least three different options on how to implement such
} 
a practice that is generally referred to as 'back-loading'. Once adopted, this would mean that fewer EUAs are released for auction initially and more later, towards the end of the trading period in 2020, which in the Commission's view would be able to address this 'temporary' market imbalance. At the same time, the European Commission has initiated a discussion on the need for 'structural' measures, in particular to address the root cause of the current imbalance (European Commission, 2012). Numerous options exist, including such one-off measures as cancelling a certain amount of allowances, introducing systemic adjustment measures or even creating new bodies (see e.g. Egenhofer et al., 2012). Whatever the final political solution, decision-making will take years to complete. The development of the EU's international strategy cannot be seen in isolation from the intricacies of the international discussion, notably since there is no consensus on either the domestic or the international aspects.

Differences of interest among member states within the Council are multi-faceted, and there is a cleavage between the 'new' and 'old' member states, i.e. those member states that were already members in 2004 when the new and newly 'independent' member states of the former Soviet area of influence joined the EU. These internal differences bear some resemblance to tensions at the international level, and this is often not understood by negotiating partners. Generally, the new member states have a far lower GDP per capita than the older member states. The poorest EU member states recorded a GDP per capita of $€ 12,600$ (Romania) and $€ 13,800$ (Bulgaria). These are levels comparable to Brazil at $€ 11,900$ and South Africa at $€ 11,100$. In many cases, this is coupled with a power sector that is predominantly coal-based. Poland is the most extreme example, with coal-based power production being responsible for a bit more than $90 \%$ of total power, which translates into $56 \%$ of total primary energy consumption. The Europe OECD average figures for comparison are $24 \%$ and $17 \%$ (Spencer, 2012). Finally, energy efficiency in industry is considerably below that in old member states. Polish energy intensity is about 2.2 times higher than the EU-27 average and 2.5 times higher than that in the old member states. ${ }^{7}$ This situation represents a kind of contradiction between intra-EU developed versus developing countries.

\subsection{The EU's share of global emissions is falling fast}

It is also increasingly becoming clear that the EU's share of global GHG emissions - currently at around $13 \%$ of the global share - is decreasing fast and will fall to around $10 \%$ in 2020 . This compares with shares for China and the US each of around 20\%. According to the International Energy Agency (IEA) in Paris, the EU's cumulative savings over the period 2008 to 2020 - the period for which the EU has capped its emissions - would represent around $40 \%$ of China's expected, annual $\mathrm{CO}_{2}$ emissions (IEA, 2008).

Figure 1 shows that even if the EU, the US and other developed countries follow an aggressive reduction pathway, such as reducing total emissions by $90 \%$ in 2050 compared with 1990, emerging economies (possibly excluding India due to its low per-capita GHG emissions) will need to reduce their emissions equally by a similar degree, although with a delay of one decade. To be able to reach a situation in which the global average mean temperature increases do not exceed $2^{\circ} \mathrm{C}$, the GHG emissions of emerging economies would need to start falling absolutely by 2020 .

action. The SWD showed, by calculations using three different models, the potential impact of backloading.

7 This is based on Eurostat figures: Polish energy intensity is 373.859 kgoe/€1,000 GDP; that of the EU27 is 167.99 and the EU-15 is 150.942. 
Figure 1. A thought experiment, showing the global emissions budget that entails a $15-30 \%$ risk of exceeding $2^{\circ} \mathrm{C}$ (top line), the Annex 1 trajectory assuming an aggressive reduction of $90 \%$ below 1990 levels by 2050 (bottom line), and the remaining carbon budget available to the non-Annex 1 (middle line)

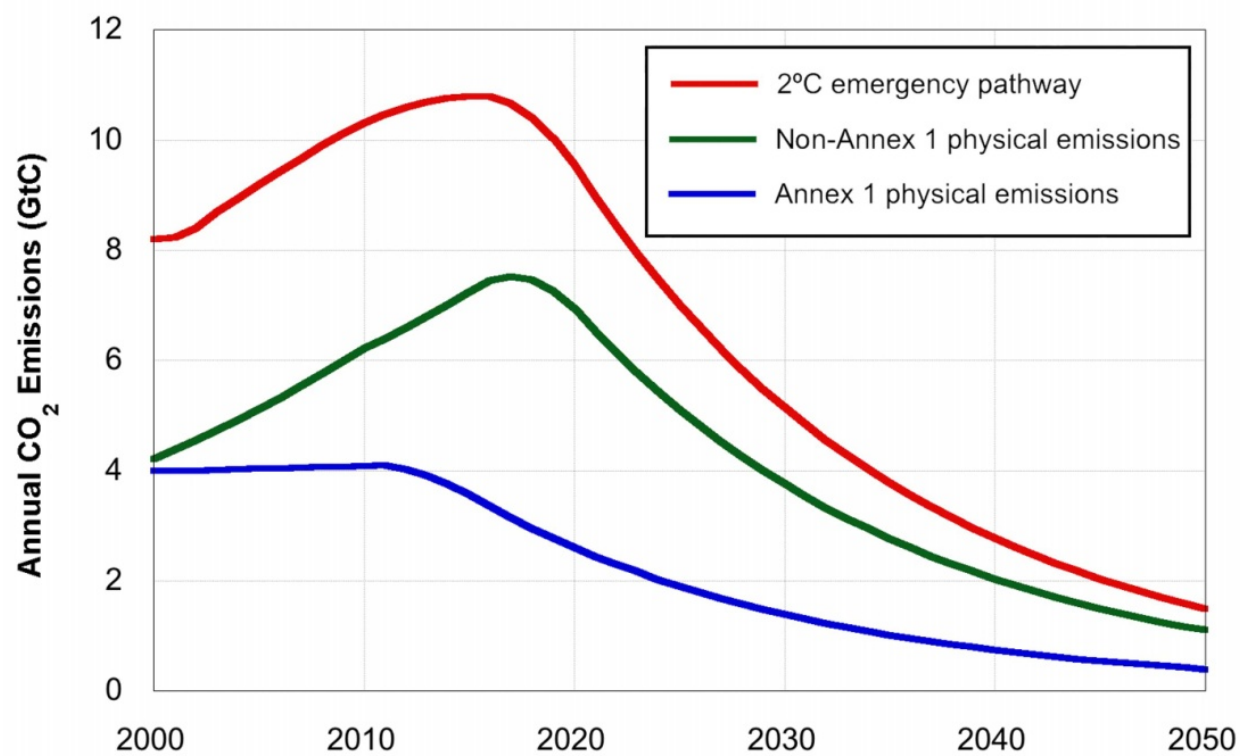

Source: Kartha et al. 2008 (ECP Report No. 5).

While there is no renouncing the notion of "common but differentiated responsibilities and respective capabilities", as enshrined in the UN Framework Convention on Climate Change (UNFCCC) ratified by more than 190 nations worldwide (including the US), it is nonetheless clear that EU reductions on their own may be laudable but are far from sufficient to address the problem. Hence, the EU's insistence on a common framework for all Parties, which was subsequently agreed in Durban when Parties agreed to "launch a process to develop a protocol, another legal instrument or an agreed outcome with legal force under the UNFCCC applicable to all Parties" to be finished by 2015 (for 2020). The increasing awareness of this situation makes the EU's unilateral commitments increasingly a hard sale.

\subsection{Industrial competitiveness does matter}

Closely related to the differentiation between developed and developing countries has been the lack of progress in 'industrial competitiveness' 8 issues. The risk of carbon leakage, whether real or perceived, will become an increasingly important impediment in the EU to raising its ambition level. Prior to Copenhagen, pressure from EU industry was relatively modest, essentially for two reasons. First, there was a prospect of some sort of global deal able to establish a 'level playing field'. Second, ETS design has been able if not to address for good, at least to park the issue. With the prospect of a global deal pushed farther away, competitiveness has again become an important matter on the EU's agenda. Competitiveness issues will be further aggravated because more European industry will need to contribute to the 'deep' costs of decarbonisation or energy transition, such as for renewable intake and massive new investment in energy infrastructure. To date, industry in all member states has

\footnotetext{
8 This term has never been defined, although roughly speaking 'competitiveness' in the context of EU climate change policy and the ETS has assumed a micro (i.e. firm or sector-specific) perspective, meaning the ability to sell, keep or increase market share, profits or stock market value or all of these at once.
} 
largely been exempted from contributing. But as costs rise, households will decreasingly be willing or able to cover the full burden. ${ }^{9}$

In the past, 'competitiveness' was addressed by free allocation in the ETS. Free allocation constitutes a form of compensation, potentially creating an incentive to continue producing in Europe. Electro-intensive industries can be compensated by state aid for additional costs stemming from carbon-induced increases in power prices.

Carbon crediting mechanisms are a second tool to address competitiveness. The extent to which crediting mechanisms are able to positively affect the competitiveness of industry in Europe by reducing compliance costs remains complex and depends on numerous conditions.

A third possibility is to include importers in the ETS or to impose an import tax on the content (i.e. including the embedded carbon) of $\mathrm{CO}_{2}$ of all goods imported into the EU from countries that do not have their own cap-and-trade system or equivalent pricing measures (see the further discussion below, in section 5.2).

A fourth possibility to deal with competiveness is to reinforce innovation and innovation policy to facilitate the transition of an industrial sector towards a low-carbon future. Such a transition will require a focus on the new value chains that a low-carbon sector could unlock. The paper and pulp industry's 2050 Roadmap to a low carbon bio-economy (CEPI, 2012) takes such an approach. According to the document, the "sector has the ambition to be at the heart of the 2050 bio-economy, an essential platform for a range of bio-based products and the recycling society". Transitions towards unlocking new value chains have happened and continue to happen in other sectors, such as steel and chemicals (see also CCAP, 2013).

\section{Building a global carbon market}

The above analysis makes it clear that the principal direction for the EU's domestic and international climate change policy will be to establish a global carbon market as soon as possible. Cap-and-trade programmes to reduce GHG emissions, or at least as a substantial element of a climate change policy, are proliferating in many regions of the world. The Kyoto mechanisms of CDM and JI have created a constituency that is likely to promote the use of emissions trading.

For the EU, emissions trading has the following attractions:

- $\quad$ over time it will create a global carbon price or at least a bandwidth of prices;

- $\quad$ such a price has the credible potential to address EU competitiveness concerns;

- $\quad$ carbon crediting mechanisms as an integral part of emissions trading operate in several ways; in the transition towards a global carbon price, they can address competitiveness concerns in the short term, they help capacity building and they link different markets;

- $\quad$ a global net of emission trading systems - as long as they are linked - will go a long way towards meeting the EU's aspirations for a global framework;

- $\quad$ if properly regulated, emission markets are efficient tools to achieve climate change objectives; and finally,

- they can be a major source of financial transfers to support least developed countries in their decarbonisation efforts.

\footnotetext{
${ }^{9}$ In the case of Germany, all costs related to the 'energy transition' of the power sector are borne by household customers. In 2012, these costs amounted to almost a quarter of the retail electricity price.
} 
For the EU, it can be seen as a success that the international climate change negotiations in Durban in December 2011 opened the way towards the creation of new market mechanisms (Marcu, 2012).

In parallel, this has triggered a review of the existing or planned mechanisms that have been under discussion for some time, for example a bilateral offset credit mechanism, sectoral crediting mechanisms, REDD-plus markets and NAMA (nationally appropriate mitigation action) crediting.

\section{Raising the ambition level}

It has become increasingly clear that raising the ambition level within the UNFCCC framework beyond the pledges in Copenhagen is extremely difficult. Therefore, there are attempts at doing so 'outside' or 'around' the UNFCCC. Several examples can be mentioned.

\subsection{Aviation and maritime}

Following the lack of progress in international fora such as the $\mathrm{UN}$, or within the International Civil Aviation Organisation (ICAO) on international aviation, the EU decided that at the start of 2012 emissions from all domestic and international flights arriving at or departing from an EU airport would be covered by the EU Emissions Trading System. The EU decided that the aviation sector would have to surrender allowances, which they receive for free or would be required to purchase.

The EU's right to cover international flights was contested by many other countries, either by political pressure or legal complaints. The most vocal opposition came from China and the US. As a result, in November 2012 the EU suspended the inclusion of international aviation following the ICAO Council meeting of 9 November, in which, according the EU, significant progress was made towards the goal of global regulation of aviation emissions.

In parallel, a similar approach is being pursued for maritime. The EU has confirmed its commitment to include these emissions in the existing EU reduction commitment should the UNFCCC processes fail to tackle them and has announced a proposal in this case. After the experience with aviation, however, it is more likely now that a solution is sought through the International Maritime Organisation.

\subsection{Carbon border measures}

Conceptually speaking, the inclusion of aviation in the ETS is comparable to a 'carbon border tax' to pursue a global 'level' pricing of carbon, i.e. to include importers in the ETS or to impose an import tax on the content (i.e. including the embedded carbon) of $\mathrm{CO}_{2}$ of all goods imported into the EU from countries that do not have their own cap-and-trade system or equivalent pricing measures. If levied by major economies, such as the US and the EU, this would most likely create a global 'shadow' carbon price even in the rest of the world. This would at least partially, through trade flows, establish carbon transfer pricing even in those parts of the world where governments have so far refrained from imposing domestic measures of any magnitude. ${ }^{10}$ Nevertheless, carbon border measures would have potential implications for world trade, international relations in general and climate negotiations, as witnessed in the controversy on including international aviation in the ETS.

\footnotetext{
${ }^{10}$ In other words, it creates a mechanism that enforces the pass-through of carbon costs across the globe, therefore making domestic consumers pay the full cost of carbon. In principle, solutions to such issues as WTO compatibility, estimating the embedded carbon or equity concerns can be found, e.g. Gros \& Egenhofer (2012).
} 


\subsection{The Climate and Clean Air Coalition}

While within the UNFCCC policy discussions on emission reductions concentrate on longlived greenhouse gases, and in particular on $\mathrm{CO}_{2}$, the role of short-lived climate pollutants (SLCPs) in reducing global warming levels and impacts in the shorter term has received less attention. Recent studies by the United Nations Environment Programme (UNEP) (2011 and UNEP \& WMO, 2011) estimate that a portfolio of low-cost abatement measures of black carbon, tropospheric ozone and methane can reduce temperature increases by $0.4-0.5 \mathrm{C}$ between 2010 and 2050. While the abatement of SLCPs can in no circumstances replace $\mathrm{CO}_{2}$ measures, addressing them in parallel has considerable benefits in the near term. Launched in February 2012, the UNEP-based Climate and Clean Air Coalition (CCAC) ${ }^{11}$ was created to develop a number of initiatives addressing i) black carbon emissions from heavy-duty diesel vehicles and engines, ii) black carbon and other pollutants from brick production, iii) SLCPs from municipal solid waste, iv) HFC alternative technology and standards, v) methane and black carbon emissions from oil and natural gas production, and other measures.

\subsection{Green growth}

More recently also within the EU, the concept of 'green growth' has gained popularity. This is partly owing to the failures of international climate negotiations, and partly to the economic stagnation following the 2008 financial crisis. The notion of green growth increasingly seems to suggest a way out of both the 'economic' and 'climate' crises. The shift to a low-carbon economy would unleash a wave of investment, innovation and more jobs. Developed countries would re-establish economic competitiveness partly due to high-tech green technologies, while developing countries and emerging economies would move on to more sustainable paths of economic development (Zysman and Huberty, 2012).

\subsection{Reducing emissions from deforestation}

Reducing emissions from deforestation or forest degradation (REDD-plus) as part of the international negotiations is a controversial issue. Within the EU, there is a consensus on the importance of attributing a value to environmental services, such as those avoiding deforestation. The importance of avoided deforestation was discussed in detail during the review of the ETS and is recognised in Article 10(3) of the ETS Directive.

To date, the sovereign participation of EU member states in the international REDD-plus market generally appears to be the most likely avenue for the EU and its member states. This approach is also seen as preferable to linking to the ETS and international carbon markets. Full linking to international carbon markets would first require more clarity in the design of REDD-plus markets, notably addressing questions of permanence, monitoring, reporting and verification and more generally compliance, as well as a solution to the tricky question of how to absorb the expected volumes of credits (e.g. O'Sullivan et al., 2010).

To date, the link to the EU ETS is the auctioning of EUAs, which will supply EU governments with funds for sovereign participation. Yet, current and expected EUA price levels are insufficient for EU financing commitments.

\subsection{Technology}

While there may be different views on whether the stabilisation of GHG emissions in line with the UNFCCC's objectives can be achieved with technically proven technology, the need

11 The state members are Australia, Bangladesh, Canada, Colombia, Denmark, Finland, France, Germany, Ghana, Israel, Italy, Japan, Jordan, Mexico, Nigeria, Norway, Sweden, the UK, the US and the European Commission. Other members include international organisations and NGOS. 
to bring carbon-efficient technologies to the market at scale more quickly is uncontroversial. Also undisputed is the need to develop, demonstrate and deploy as yet unproven technologies, in order to reach climate change targets beyond 2050. This is evidenced by the EU's SET-Plan, which has put a special emphasis on a long-term agenda of energy research, demonstration and innovation for Europe in order to make low-carbon technologies affordable and competitive and thereby enable market uptake to meet the EU 2020 targets, as well as to realise its 2050 vision of a low-carbon economy.

The IEA's Energy Technology Perspectives 2012, however, finds that progress in almost all technologies (i.e. nuclear, clean coal, CCS in power, CCS in industry, buildings and biofuels in industry) is not where it needs to be to meet global ambitions for GHG emission reductions. The notable exceptions are renewables and to a degree industry, vehicle fleet economy and electrical vehicles, where there is progress but additional effort would be required to meet targets.

\section{Areas for cooperation}

Both the failure of the Copenhagen climate change negotiations and the economic crisis caught the EU off guard. Since the demise of the Kyoto-style top-down world of legally binding emission 'targets' for developed countries and 'actions' for developing countries, and the subsequent substitution by a bottom-up approach based on voluntary pledges (with or without review), the EU has struggled to find a new climate change consensus. Although support for climate change policy is still very high among politicians and citizens alike, discussions on the distribution of costs and benefits among sectors, regions and member states have become more acrimonious.

The EU has also realised that 'leadership' requires followers. In Copenhagen, there was little if any interest in the EU's offer to increase its ambition level to 30\% GHG emission reductions in 2020 compared with 1990. The EU's negotiation partners were rather preoccupied with replacing the top-down architecture of the Kyoto Protocol with a bottomup model of voluntary pledges.

While there might be a comprehensive and legally binding, global climate change agreement that the EU had so hoped for, it will significantly fall short of the EU's declared ambitions. Hence, the matter of a level playing field for EU industry, especially in times of economic crisis and uncertainty, will become more important and may hold back a new EU consensus.

The best way to address this from the EU perspective is through the (gradual) establishment of a global carbon market. In addition to being able to address competitiveness in both the short and long term, a global carbon market would go a long way towards setting up a framework for global climate change policy as well as offering the possibility to address climate finance. This could also give a boost to low-carbon technology deployment and possibly to technology development.

While all this does not offer any hope of keeping the global average increase in mean temperature to below $4^{\circ} \mathrm{C}$ or $3^{\circ} \mathrm{C}$ at best, the EU along other countries is trying to increase the level of ambition, mainly by working outside but not against the UN framework. Aviation, shipping and short-lived climate pollutants are examples in this regard. Other potential areas might be REDD-plus or certain 'green growth' themes, including finance.

This opens the door to a different approach. Owing to positive domestic changes in Brazilian climate policy, as well as Brazil's willingness to collaborate, the EU may seize the opportunity to counterbalance the present lack of influence originating from its own domestic climate policy by engaging in effective bilateral assistance to Brazil. In doing so, the 
EU may also be able to engage further with other BRIC countries, by demonstrating the benefits of collaboration. The EU could regain some influence as well as bring some additional momentum to its industrial policy in the area of low carbon technologies.

There is actually strong interest in technology cooperation on the part of Brazil. First, this would point to joint research cooperation with the EU and its member states, and capacity building would be a key building block in this respect (e.g. transferring managerial and organisational capabilities). Fields for 'technology transfer' that regularly appear on the list of areas for cooperation (such as CCS, smart grids, solar and wind energy, and energy efficiency), on the other hand, will require further work to identify the public policy issues. Technology transfer typically is integral to trade and notably investment, where industry deploys and therefore transfers technologies. Public policy issues outside R\&D cooperation remain limited in scope.

Possible initial actions might be for the EU to offer better market access to bio-ethanol or reduce trade barriers for second-generation ethanol. Still, it must be said that the high number of cars with diesel engines in the EU somewhat reduces the market potential for bioethanol.

Of course, a move to increase its domestic ambition level from a situation in which it is very close to having achieved its unilateral targets of $-20 \%$ because of the economic crisis and other events unrelated to climate change policy would support the EU's position towards its partners. How this will play out is impossible to say at this stage. 


\section{Bibliography}

Center for Clean Air Policy (CCAP) (2013), The New Deal: An Enlightened Industrial Policy for the EU through Structural ETS Reform, CCAP, Washington D.C. and Brussels.

Confederation of European Paper Industries (CEPI) (2012), Unfold the future: The forest fibre industry 2050 Roadmap to a low carbon bio-economy, CEPI, Brussels.

Den Elzen, M., M.A. Mendoza Beltran, J. van Vliet, S.J.A. Bakker and T. Bole (2009), Pledges and Actions, Report No. 500102032 2009, Netherlands Environmental Assessment Agency, The Hague.

European Environment Agency (EEA) (2009), Annual European Community greenhouse gas inventory 1990-2007 and inventory report 2009: Submission to the UNFCCC Secretariat, EEA Technical Report No. 4/2009, EEA, Copenhagen.

Egenhofer, C. (2007), “The Making of the EU Emissions Trading Scheme: Status, Prospects and Implications for Business", European Management Journal, Vol. 25, No. 6, December, pp. 453-463.

Egenhofer, C., M. Alessi, A. Georgiev and N. Fujiwara (2011), The EU Emissions Trading Scheme and Climate Policy towards 2050, CEPS Special Report, CEPS, Brussels.

Egenhofer, C., A. Marcu and A. Georgiev (2012), Reviewing the EU ETS Review? CEPS Task Force Report, CEPS, Brussels, October.

Ellerman, A.D. and P. Joskow (2008), The European Union's Emissions Trading System in Perspective, Pew Center on Global Climate Change, Arlington, VA, May.

Ellerman, A.D., F. Convery and C. de Perthuis (2010), Pricing Carbon: The European Union Emissions Trading Scheme, Cambridge: Cambridge University Press.

European Commission (2009), Stepping up international climate finance: A European blueprint for the Copenhagen deal, Communication from the Commission, $\operatorname{COM}(2009)$ 475/3, Brussels.

(2010a), Analysis of options to move beyond 20\% greenhouse gas emission reductions and assessing the risk of carbon leakage, Communication from the Commission COM(2010) 265/3 (unofficial version), Brussels.

(2010b), Commission Staff Working Document, accompanying the European Commission Communication, Analysis of options to move beyond 20\% greenhouse gas emission reductions and assessing the risk of carbon leakage, Communication from the Commission, SEC(2010) 650/2, Background information and analysis, Part II (unofficial version), Brussels, p. 40.

(2012), The state of the European carbon market in 2012, Report from the Commission to the European Parliament and the Council, COM(2012) 652, 14 November, Brussels.

Gros, D. and C. Egenhofer (2011), "The case for taxing carbon at the border", Climate Policy, Vol. 11, No. 5, Special Issue, pp. 1212-1225.

International Monetary Fund (IMF) (2009), World Economic Outlook Database, IMF, Washington, D.C., October.

International Energy Agency (IEA) (2008a), World Energy Outlook 2008, OECD/IEA, Paris. (2008b), Climate Policy and Carbon Leakage, IEA Information Paper, OECD/IEA, Paris, October. 
(2012), Energy Technology Perspectives 2012, International Energy Agency, OECD/IEA, Paris.

Kartha, S., B. Kjellen, P. Baer and T. Athanasiou (2008), Linking measurable, reportable and verifiable mitigation actions by developing countries to measurable, reportable and verifiable financial and technical support by developed countries, Background Paper No. 1 of ECP Report No. 5, European Climate Platform, CEPS, Brussels.

Marcu, A. (2012), "The Durban Outcome: A Post-2012 Framework Approach for Greenhouse Gas Markets", in UNEP Risoe Centre (ed.), Progressing towards post-2012 carbon markets, UNEP Risoe Center, Roskilde, pp. 127-138.

O'Sullivan, R., C. Streck, T. Pearson, S. Brown and A. Gilbert (2010), Engaging the private sector in the potential generation of carbon credits from REDD+: An analysis of issues, Report to the UK Department for International Development, Climate Focus, Amsterdam.

Skjærseth, J.B. and J. Wettestad (2010), "Fixing the EU Emissions Trading System? Understanding the Post-2012 Changes", Global Environmental Politics, Vol. 10, No. 4, pp. 101-123.

Spencer, T., K. Tangen and A. Korppoo (2010), The EU and the Global Climate Regime: Getting back into the game, Briefing Paper No. 55, Finnish Institute of International Affairs, Helsinki, February.

Spencer, T. (2012), "Time for a grand bargain with Poland on energy and climate", European Energy Review, 8 March.

Swedish Energy Agency (2007), The EU Emissions Trading Scheme after 2012, Swedish Environmental Protection Agency and Swedish Energy Agency, Eskilstuna.

United Nations Environment Programme (UNEP) (2011), Near-term Climate Protection and Clean Air Benefits: Actions for Controlling Short-Lived Climate Forcers, UNEP Synthesis Report, UNEP, Nairobi.

United Nations Environment Programme (UNEP) and World Meteorological Organization (WMO) (2011), Integrated Assessment of Black Carbon and Tropospheric Ozone - Summary for Decision Makers, UNEP, Nairobi.

Ward, M. and M. Grubb (2009), Comparability of Effort by Annex 1 Parties: An Overview of Issues, Climate Strategies, London.

Zysman, J. and M. Huberty (2012), "Religion and Reality in the Search for Green Growth", Intereconomics, Vol. 45, No. 3, pp. 140-146. 


\section{Appendix}

Table A1. National overall targets for the share of energy from renewable sources in gross final consumption of energy in 2020 and member state GHG emission limits in non-ETS sectors for the period 2013-20 (\%)

\begin{tabular}{|c|c|c|c|}
\hline Member state & $\begin{array}{l}\text { Share of energy } \\
\text { from renewable } \\
\text { sources in gross } \\
\text { final consumption } \\
\text { of energy, } 2005\end{array}$ & $\begin{array}{l}\text { Target for share of } \\
\text { energy from } \\
\text { renewable sources in } \\
\text { gross final } \\
\text { consumption of } \\
\text { energy, 2020 }\end{array}$ & $\begin{array}{l}\text { Member state GHG } \\
\text { emission limits in } 2020 \\
\text { compared with 2005, } \\
\text { GHG emission levels } \\
\text { (from sources not } \\
\text { covered by the ETS) }\end{array}$ \\
\hline Austria & 23.3 & 34 & -16 \\
\hline Belgium & 2.2 & 13 & -15 \\
\hline Bulgaria & 9.4 & 16 & 20 \\
\hline Czech Republic & 6.1 & 13 & 9 \\
\hline Cyprus & 2.9 & 13 & -5 \\
\hline Denmark & 17 & 30 & -20 \\
\hline Estonia & 18.0 & 25 & 11 \\
\hline Finland & 28.5 & 38 & -16 \\
\hline France & 10.3 & 23 & -14 \\
\hline Germany & 5.8 & 18 & -14 \\
\hline Greece & 6.9 & 18 & -4 \\
\hline Hungary & 4.3 & 13 & 10 \\
\hline Ireland & 3.1 & 16 & -20 \\
\hline Italy & 5.2 & 17 & -13 \\
\hline Latvia & 32.6 & 40 & 17 \\
\hline Lithuania & 15.0 & 23 & 15 \\
\hline Luxembourg & 0.9 & 11 & -20 \\
\hline Malta & 0 & 10 & 5 \\
\hline The Netherlands & 2.4 & 14 & -16 \\
\hline Poland & 7.2 & 15 & 14 \\
\hline Portugal & 20.5 & 31 & 1 \\
\hline Romania & 17.8 & 24 & 19 \\
\hline Slovak Republic & 6.7 & 14 & 13 \\
\hline Slovenia & 16.0 & 25 & 4 \\
\hline Spain & 8.7 & 20 & -10 \\
\hline Sweden & 39.8 & 49 & -17 \\
\hline UK & 1.3 & 15 & -16 \\
\hline
\end{tabular}

Source: European Commission website. 


\section{ABOUT CEPS}

Founded in Brussels in 1983, the Centre for European Policy Studies (CEPS) is widely recognised as the most experienced and authoritative think tank operating in the European Union today. CEPS acts as a leading forum for debate on EU affairs, distinguished by its strong in-house research capacity, complemented by an extensive network of partner institutes throughout the world.

\section{Goals}

- Carry out state-of-the-art policy research leading to innovative solutions to the challenges facing Europe today,

- Maintain the highest standards of academic excellence and unqualified independence

- Act as a forum for discussion among all stakeholders in the European policy process, and

- Providea regular flow of authoritative publications offering policy analysis and recommendations,

\section{Assets}

- Multidisciplinary, multinational \& multicultural research team of knowledgeable analysts,

- Participation in several research networks, comprising other highly reputable research institutes from throughout Europe, to complement and consolidate CEPS' research expertise and to extend its outreach,

- An extensive membership base of some 132 Corporate M embers and 118 Institutional Members, which provide expertise and practical experience and act as a sounding board for the feasi bility of CEPS policy proposals.

\section{Programme Structure}

\section{In-house Research Programmes}

\section{Economic and Social Welfare Policies}

Financial Institutions and Markets

Energy and Climate Change

EU Foreign, Security and Neighbourhood Policy

Justice and Home Affairs

Politics and Institutions

Regulatory Affairs

Agricultural and Rural Policy

\section{Independent Research Institutes managed by CEPS}

European Capital Markets Institute (ECMI)

European Credit Research Institute (ECRI)

\section{Research N etworks organised by CEPS}

European Climate Platform (ECP)

European N etwork for Better Regulation (ENBR)

European N etwork of Economic Policy

Research Institutes (ENEPRI)

European Policy Institutes N etwork (EPIN) 